\title{
Research Concerning the Dynamic Model of the Conventional Sucker Rod Pumping Units
}

\author{
GEORGETATOMA* \\ Petroleum-Gas University of Ploiesti, 39 Bucuresti Blvd., 100680, Ploiesti, Romania
}

\begin{abstract}
The study of the dynamic model of the conventional sucker rod pumping units requires first determining the variation on the cinematic cycle of the synthesis parameters (the reduced moment and the reduced mass moment of inertia) and then the variation of the angular speed of the cranks, in response to the dynamic and resistant actions on the component elements that appear during operation. The paper presents the way of determining the variation on the cinematic cycle of the synthesis parameters of the dynamic model corresponding to the conventional pumping unit mechanism and of the variation of the angular speed of its cranks. The experimental records have been processed with the Total Well Management program. The simulations have been performed with a computer program developed by the author using the Maple programming environment.
\end{abstract}

Keywords: conventional sucker rod pumping unit, dynamic model, synthesis parameters

Modeling the dynamics of the conventional sucker rod pumping installations represents an issue of study of prime importance for their optimal design [1-9]. In this scope the study of the dynamic model, namely determining the variation on the cinematic cycle of the synthesis parameters (the reduced moment and the reduced mass moment of inertia) and the variation of the angular speed of the cranks may lead to a better understanding of the influence of various functional or constructive parameters on the behavior of the sucker rod pumping installations in service [10-15].

In this paper is analyzed the dynamic model of the conventional sucker rod pumping installations. It is presented the way of determining the variation on the cinematic cycle of the synthesis parameters and of the angular speed of the cranks. Some significant results concerning the cinematic and dynamic analysis of the plane mechanisms that have strongly helped to the achievement of the research from this paper are presented in [16-23]. The simulations have been performed with a computer program developed by the author using the Maple programming environment [24] and the experimental records have been processed with the Total Well Management program [25].

\section{Experimental part}

It was used the program Total Well Management [25] for processing the experimental records in the case of a well serviced by a C-640D-305-120 pumping unit manufactured by Lufkin (fig. 1).

For establishing the variation of the synthesis parameters and of the angular speed of the cranks were used the variation of the force at the polished rod and the variation of the motor moment at the crankshaft during the stroke 65 represented in figure 2 and figure 3 , respectively.

Establishing the variation on the cinematic cycle of the synthesis parameters and of the angular speed of the cranks

In figure 4 is represented a conventional pumping unit mechanism. $\mathrm{C}_{1}, \mathrm{C}_{2}$ and $\mathrm{C}_{3}$ are the mass centers of the cranks, connecting rods and of the rocker, respectively; $m_{c G}$ is the total mass of the balancing counterweights; $\mathrm{m}_{\mathrm{L} 1}$ is the total mass of the connecting bearings between

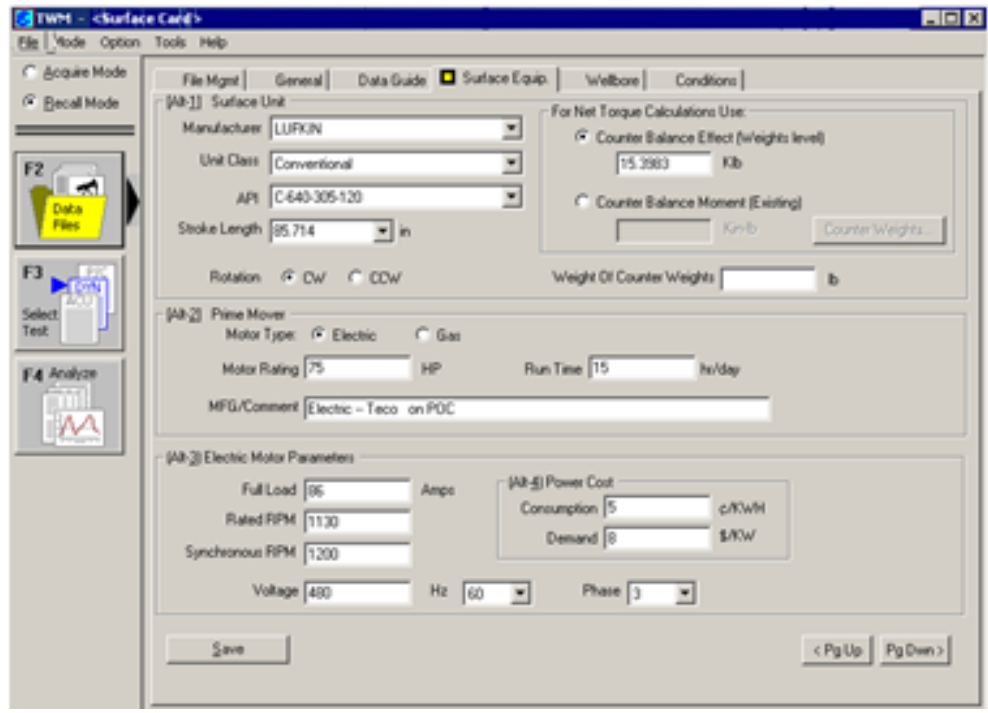

Fig. 1. Data concerning the analyzed well

* email: georgeta_tm@yahoo.com 


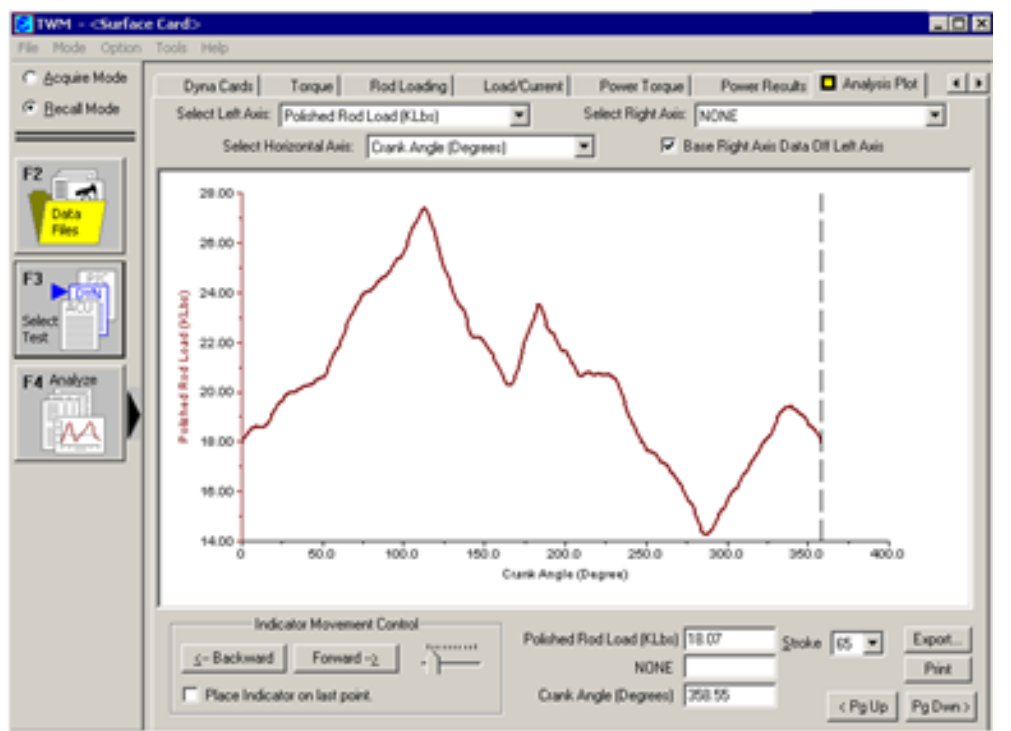

Fig. 2. The variation of the force at the polished rod during the stroke 65

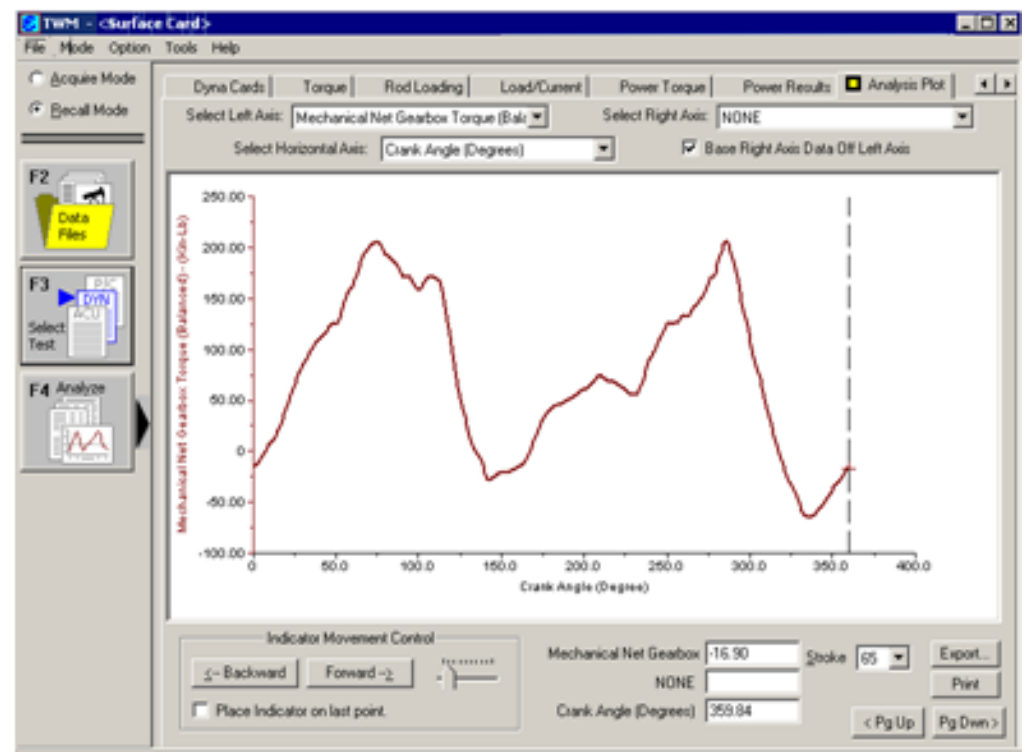

Fig. 3. The variation of the motor moment at the crankshaft during the stroke 65

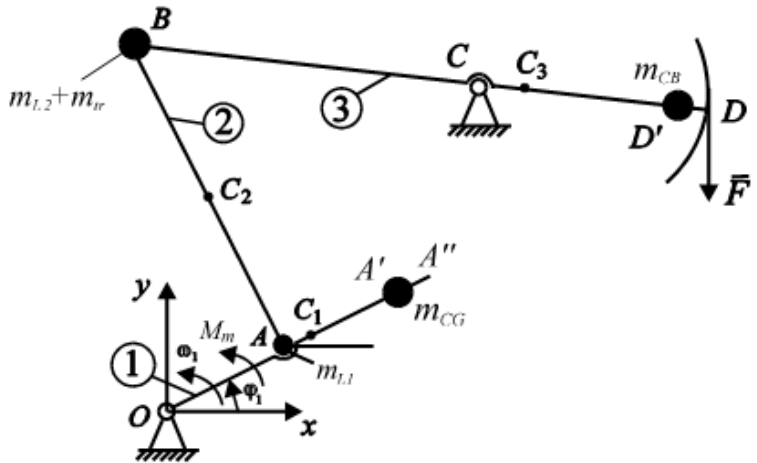

Fig. 4. Conventional sucker rod pumping unit mechanism the cranks and the connecting rods; $m_{L}$ is the mass of the spherical connecting bearing between the connecting rods and the rocker; $m_{\text {tr }}$ is the mass of the equalizer traverse; $\mathrm{m}_{\mathrm{CB}}$ is the mass of the rocker head considered to be concentrated in point $D^{\prime} ; M_{\text {is }}$ is the motor moment at the crankshaft; $F$ is the force acting at the end of the polished rod.

The synthesis parameters of the dynamic model of a plane mechanism, namely the reduced mass moment of inertia $J_{\text {red }}$ and the reduced moment $\mathrm{M}_{\text {red }}$, can be calculated from the following relations [22]:

$$
\begin{aligned}
& \frac{1}{2} \cdot J_{r e d} \cdot \omega_{1}^{2}=\sum_{j}\left(\frac{1}{2} \cdot m_{j} \cdot v_{C j}^{2}+\frac{1}{2} \cdot J_{C j} \cdot \omega_{j}^{2}\right) \\
& \bar{M}_{r e d} \cdot \bar{\omega}_{1}=\sum\left(\bar{F}_{j} \cdot \bar{v}_{C_{j}}+\bar{M}_{j} \cdot \bar{\omega}_{j}\right) \\
& \frac{1}{2} \cdot J_{n t d} \cdot \omega_{1}^{2}=\frac{1}{2} \cdot m_{1} \cdot v_{c 1}^{2}+\frac{1}{2} \cdot m_{2} \cdot v_{c 2}^{2}+\frac{1}{2} \cdot m_{3} \cdot v_{c 3}^{2}+\frac{1}{2} \cdot m_{L 1} \cdot v_{A}^{2}+\frac{1}{2} \cdot\left(m_{L 2}+m_{b}\right) \cdot v_{B}^{2}+ \\
& +\frac{1}{2} \cdot m_{C G} \cdot v_{D^{\prime}}^{2}+\frac{1}{2} \cdot m_{C G} \cdot v_{A^{*}}^{2}+\frac{1}{2} \cdot J_{C 1} \cdot \omega_{1}^{2}+\frac{1}{2} \cdot J_{C 2} \cdot \omega_{2}^{2}+\frac{1}{2} \cdot J_{C 3} \cdot \omega_{3}^{2} \\
& \bar{M}_{r t d} \cdot \bar{\omega}_{1}=\bar{G}_{1} \cdot \bar{v}_{c 1}+\bar{G}_{2} \cdot \bar{v}_{c 2}+\bar{G}_{3} \cdot \bar{v}_{c 3}+\bar{G}_{L 1} \cdot \bar{v}_{A}+\left(\bar{G}_{L 2}+\bar{G}_{b r}\right) \cdot \bar{v}_{B}+ \\
& +\bar{G}_{C g} \cdot \bar{v}_{D^{\prime}}+\bar{G}_{C G} \cdot \bar{v}_{A^{\prime}}+\bar{F} \cdot \bar{v}_{D}+\bar{M}_{m} \cdot \bar{\omega}_{1}
\end{aligned}
$$


where: $m_{1}, m_{2}$ and $m_{3}$ are the masses of the cranks, of the connecting rods and of the rocker, respectively, and $J_{\mathrm{Cl}_{1}} J_{\mathrm{C} 2}$ and $J_{C_{3}}$ are their mass moments of inertia.

The manner of establishing the variation on the cinematic cycle of the speed of different points situated on the pumping units mechanism is presented in [9]. In [9] is also presented the manner of calculating of the crank

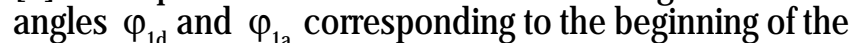
upward and downward movements of the sucker rod column.

The variation on the cinematic cycle of the angular speed of the cranks $\omega_{1}$ can be obtained by integrating the movement equation of the pumping unit mechanism with the following relation [22]:

$$
\omega_{1}\left(\varphi_{1}\right)=\sqrt{\frac{J_{r e d, 0}}{J_{r e d}} \cdot \omega_{1,0}^{2}+\frac{2}{J_{r e d}} \cdot \int_{\varphi_{1,0}}^{\varphi_{1}} M_{r e d}\left(\varphi_{1}\right) \mathrm{d} \varphi_{1}}
$$

where: $\omega_{1,0}$ and $J_{\text {red, },}$ are the values of $\omega_{1,0}$ and $J_{\text {red, }, 0}$ respectively, at the beginning of the cinematic cycle corresponding to the cranks angle $\varphi_{1,0}$.

\section{Results and discussions}

The simulations have been performed in the case of a C-640D-305-120 pumping unit produced by Lufkin [26] with a computer program developed by the author using Maple programming environment [24]. The component elements of the pumping unit mechanism (fig. 4) have the following dimensions: $O A=30$ in. (0.762 $\mathrm{m}) ; A B=133.5 \mathrm{in}$. (3.3909 $\mathrm{m}) ; B C=111.09$ in. $(2.8217 \mathrm{~m}) ; C D=155 \mathrm{in} .(3.937 \mathrm{~m})$. The coordinates of the point $C$ (fig. 4) are: $x_{C}=(2.8194 \mathrm{~m})$ and $\mathrm{y}_{\mathrm{c}}=(3.5052 \mathrm{~m})$. The values of the crank angle $\varphi_{d}$ corresponding to the beginning of the upward and downward movements of the sucker rod column are: $\varphi_{1 \mathrm{~d}}$ $=88.976^{\circ}$ and $\varphi_{1 \mathrm{a}}=266.929^{\circ}$, respectively.

The other parameters involved in calculations have the following values: $O A^{\prime}=46 \mathrm{in}$. (1.1684 m); $O A^{\prime \prime}=95 \mathrm{in}$. $(2.413 \mathrm{~m}) ; C D^{\prime}=140 \mathrm{in} .(3.556 \mathrm{~m}) ; \mathrm{m}=88 \mathrm{~kg} ; \mathrm{m}_{12}=169 \mathrm{~kg}$; $\mathrm{m}_{\mathrm{tr}}=580 \mathrm{~kg} ; \mathrm{m}_{\mathrm{CB}}=840 \mathrm{~kg} ; \mathrm{m}_{\mathrm{CG}}=5200 \mathrm{~kg} ; q_{1}=722 \mathrm{~kg} / \mathrm{m}$; $q_{2}=34 \mathrm{~kg} / \mathrm{m} ; q_{3}=300 \mathrm{~kg} / \mathrm{m}\left(q_{1}, q_{2}\right.$, and $q_{3}$ are the linear masses of the cranks, connecting rods and of the rocker, respectively). The nominal angular speed of the cranks is of $6.667 \mathrm{rot} / \mathrm{min}$.

In figure 5 is represented the variation of the reduced moment $M_{\text {red }}$ during the stroke 65 and in figure 6 is presented the variation of the reduced mass moment of inertia $J_{\text {red }}$ during a cinematic cycle. In both cases the variation is considered beginning with the angle $\varphi_{1 \mathrm{~d}}$.

$A$ way to validate the variation on a cinematic cycle of the reduced moment $\mathrm{M}_{\text {red }}$ is to verify if $\int_{\phi c} M_{r e d}\left(\varphi_{1}\right) \mathrm{d} \varphi_{1}=0$ [22]. In figure 7 is represented the variation during the stroke 65 of the kinetic energy [22]: $\Delta E_{c}\left(\varphi_{1}\right)=\int_{\varphi_{i d}}^{\varphi_{1}} M_{r e d}\left(\varphi_{1}\right) \mathrm{d} \varphi_{1}$, where $\varphi_{1} \in\left[\varphi_{1 d}, \varphi_{1 d}+2 \pi\right]$. It can be observed that $\Delta E_{c}\left(\varphi_{1 d}+2 \pi\right)=\int_{\phi c} M_{r e d}\left(\varphi_{1}\right) \mathrm{d} \varphi_{1}$ is not exactly equal to zero, but is very close to zero. This little difference occurs especially due to the errors in the recording of the values of the force at the polished rod and of the motor moment at the crankshaft.

In figure 8 is represented the variation during the stroke 65 of the angular speed of the cranks expressed in rot/min. In applying the relation (5) has been considered that $\omega_{1,0}$ is equal to the nominal angular speed of the cranks.
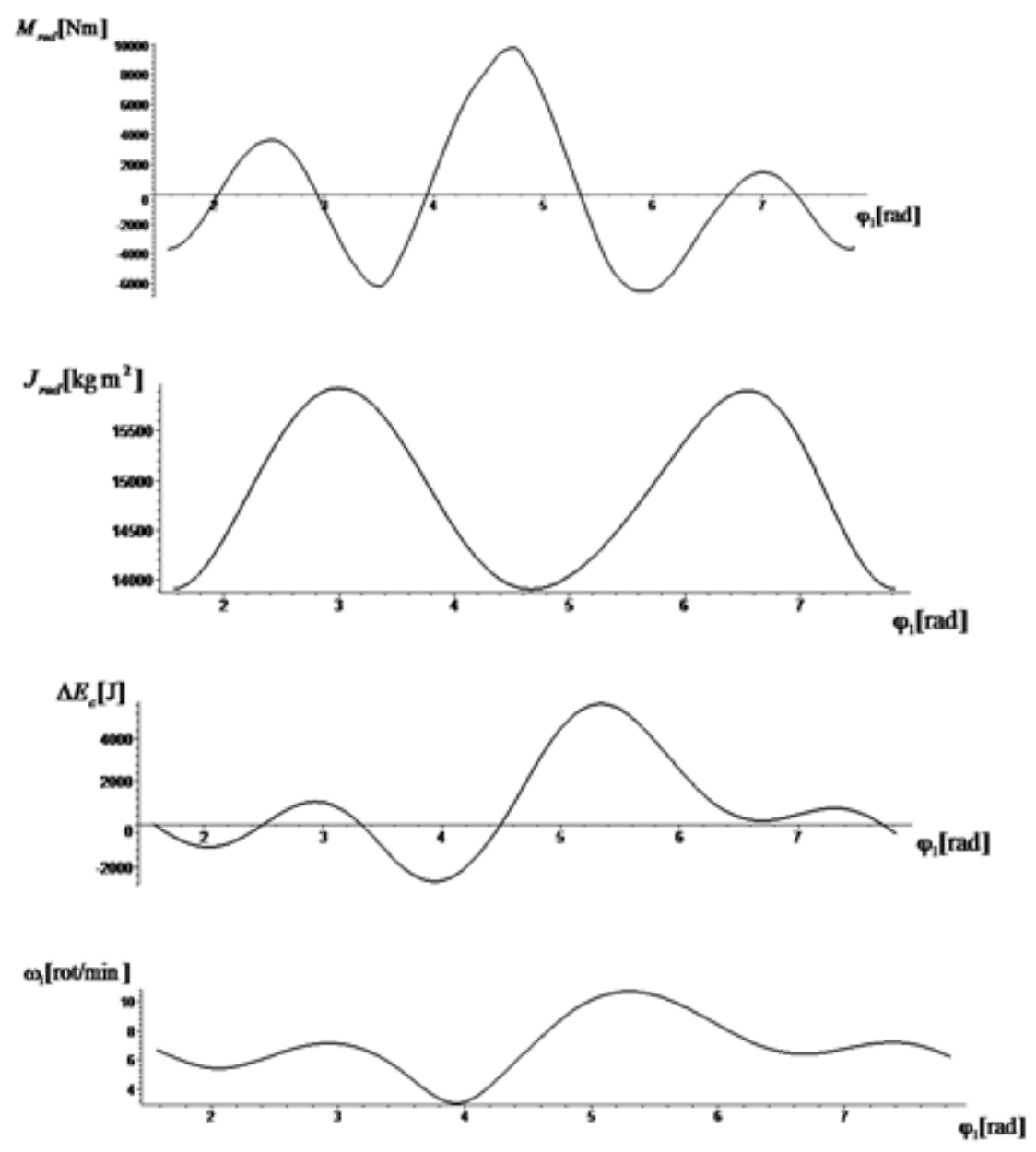

Fig. 5. The variation of the reduced moment during the stroke 65

Fig. 6. The variation of the reduced mass moment of inertia during a cinematic cycle

Fig. 7. The variation of the kinetic energy during the stroke 65

Fig. 8. The variation of the angular speed of the cranks during the stroke 65 


\section{Conclusions}

In this paper has been analyzed the dynamic model of the conventional sucker rod pumping units. It has been presented the way of determining the variation on the cinematic cycle of the synthesis parameters of the dynamic model and of the angular speed of the cranks. Some results concerning a way to validate the variation on a cinematic cycle of the reduced moment have been also presented.

\section{References}

1.GIBBS, S G., Predicting the behavior of sucker-rod pumping systems, Journal of Petroleum Technology, 1963 (J uly), p. 769-778

2.POPOVICl, A., Equipment for the exploitation of oil wells (in Romanian), Technical Publishing House, Bucharest, 1989

3.BADOIU, D., TOMA, G., Research concerning the identification of some parameters of a sucker rod pumping unit, Rev. Chim. (Bucharest), 68, no. 10, 2017, p. 2289-2292

4.BADOIU, D., TOMA, G., Research concerning the kinetostatic analysis of the mechanism of the conventional sucker rod pumping units, Rev. Chim. (Bucharest), 69, no. 7, 2018, p. 1855-1859

5.BADOIU, D., TOMA, G., Research concerning the correlations between some experimental results in the case of a sucker rod pumping installation, Rev. Chim. (Bucharest), 69, no. 11, 2018, p. 3060

6.BADOIU, D., TOMA, G., Research concerning the predictive evaluation of the motor moment at the crankshaft of the conventional sucker rod pumping units, Rev. Chim. (Bucharest), 70, no. 2, 2019, p. 378

7.BADOIU, D., Research concerning the use of polynomial functions in the study of the conventional sucker rod pumping units, Rev. Chim. (Bucharest), 70, no. 4, 2019, p. 1223

8.TOMA, G., Research concerning the optimization of the mechanism of the conventional sucker rod pumping units, Rev. Chim. (Bucharest), 70, no. 5, 2019, p. 1795

9.TOMA, G., BADOIU, D., Research concerning the influence of some constructive errors on the dynamics of a pumping unit, PetroleumGas University of Ploiesti Bulletin, Technical Series, Vol. 63, no. 4, 2011, p. 27-30

10.BADOIU, D., TOMA, G., On a dynamic optimisation problem of the quadrilateral mechanism, Journal of the Balkan Tribological Association, Vol. 22, no. 1, 2016, p. 250-260

11.BADOIU, D., On the dynamic behavior of a quadrilateral mechanism, Petroleum-Gas University of Ploiesti Bulletin, Technical Series, Vol. 64, no. 2, 2012
12.VASILESCU, S., BADOIU, D., On the dynamic analysis of a family of quadrilateral mechanisms, Petroleum-Gas University of Ploiesti Bulletin, Technical Series, Vol. 63, no. 2, 2011, p. 7-10

13.BADOIU, D., On the movement equation of the quadrilateral mechanism, Petroleum-Gas University of Ploiesti Bulletin, Technical Series, Vol. 67, no. 2, 2015, p. 67-72

14.BADOIU, D., On the calculus of the equilibrium moment in the case of a plane mechanism, Petroleum-Gas University of Ploiesti Bulletin, Technical Series, Vol. 62, no. 4B, 2010, p. 23-28

15.BADOIU, D., On the calculus of the necessary motor moment for the running of the plane mechanisms, Petroleum-Gas University of Ploiesti Bulletin, Technical Series, Vol. 61, no. 4, 2009, p. 79-82

16.BADOIU, D., Research concerning the dynamic analysis of plane mechanisms structures, Petroleum-Gas University of Ploiesti Bulletin, Technical Series, Vol. 61, no. 2, 2009, p. 29-32

17.BADOIU, D., On the establishing and solving of the movement equation in the case of the plane mechanisms, Petroleum-Gas University of Ploiesti Bulletin, Technical Series, Vol. 67, no. 3, 2015, p. 87-93

18.TOMA, G., BADOIU, D., On the cinematic analysis of a mechanism of fourth class, Petroleum-Gas University of Ploiesti Bulletin, Technical Series, Vol. 64, no. 1, 2012, p. 69-72

19.TOMA, G., BADOIU, D., Research Concerning the Calculus of the Equilibrium Moment in the Case of a Plane Mechanism Using the Dynamic Model, Petroleum-Gas University of Ploiesti Bulletin, Technical Series, Vol. 67, no. 2, 2015, p. 93-98

20.BADOIU, D., On the calculus of the equilibrium moment for a mechanism with three independent contours, Petroleum-Gas University of Ploiesti Bulletin, Technical Series, Vol. 67, no. 1, 2015, p. 99-104

21.BADOIU, D., On the positional and cinematic analysis of a mechanism with three independent contours, Petroleum-Gas University of Ploiesti Bulletin, Technical Series, Vol. 66, no. 2, 2014, p. 55-58

22.BADOIU, D., Dynamic analysis of mechanisms and machines (in Romanian), Didactical and Pedagogical Publishing House, Bucharest, 2003

23.SHIGLEY, J.E., UICKER JR., J.J., Theory of machines and mechanisms, McGraw-Hill, 1981

24.MONAGAN, M.B., GEDDES, K.O., HEAL, K.M., LABAHN, G., VORKOETTER, S.M., MCCARRON, J , DEMARCO, P., Maple Introductory Programming Guide, Maplesoft, a division of Waterloo Maple Inc., 2005

25.*** Total Well Management Help Manual, Echometer Company, Texas

26.*** Conventional Crank Balanced Pumping Units, Lufkin Oilfield Products Group, Houston, Texas

Manuscript received: 5.09 .2018 